\title{
UAS LIDAR MAPPING OF AN ARCTIC TUNDRA WATERSHED: CHALLENGES AND OPPORTUNITIES
}

\author{
A. D. Collins ${ }^{1}$, C. G. Andresen ${ }^{1+}$, L. M. Charsley-Groffman ${ }^{1 \dagger}$, T. Cochran ${ }^{2}$, J. Dann ${ }^{1}$, E. Lathrop ${ }^{1}$, G. J. Riemersma ${ }^{2}$, E. M. \\ Swanson $^{1}$, A. Tapadinhas ${ }^{2}$, C. J. Wilson ${ }^{1}$ \\ ${ }^{1}$ Earth and Environmental Sciences Division, Los Alamos National Laboratory, Los Alamos, NM 87545, USA -(acollins, jdann, \\ elathrop, emswanson, cjw)@lanl.gov; \\ ${ }^{2}$ Routescene, Inc, 200 Troon Trail Durango, CO 81301, USA - tomcochran3@ routescene.com, gjr@mapix.com, andre@mapix.com \\ ${ }^{\ddagger}$ Current Affiliation: Department of Geography, University of Wisconsin-Madison, Madison, WI 53706, USA - \\ candresen@wisc.edu; \\ ${ }^{\dagger}$ Current Affiliation: Landpro Ltd., 13 Pinot Noir Drive, PO Box 302, Cromwell, Central Otago 9342, New Zealand - \\ lauren@landpro.co.nz
}

KEY WORDS: Arctic, Best practices, Drone, LiDAR, UAS

\begin{abstract}
:
Uncrewed aircraft systems (UAS) are increasingly used across disciplines in academic research. We deployed a heavy-lift UAS (<25 $\mathrm{kg}$ ) for research in the Arctic tundra, a remote and complex landscape. Conducting UAS work in this location required adapting our standard field approach to include both the unique challenges of working in these locations with those specific to UAS work. We collected metadata on each field campaign and analyzed our expended efforts and the contributors to our successes and failures. We formulated a set of best practices to address each challenge in a systematic way, addressing each with the underlying goals of maximizing system and team resilience, operational efficiency, and safety. By adopting a structured set of best practices tenets into our UAS work in the Arctic, we achieved greater project success and we recommend integrating such methods into similar projects of high importance or consequence, especially for UAS LiDAR work in the Arctic.
\end{abstract}

\section{INTRODUCTION}

Recent advancements in technology sectors including lithium batteries, microelectronics such as accelerometers, and multirotor software has allowed multiple manufacturers to develop and bring low cost uncrewed aircraft systems (UAS) options to market. As the UAS user base began to change from being dominated by hobbyists or highly-specified professionals to consumers, product offerings started to incorporate larger airframes and additional safety features that made adoption possible by industrial and research organizations, requiring the ability to deploy heavier payloads for multiple uses. Now, in parallel with increases in stability and endurance of UAS platforms, miniaturization is occurring in a wide variety of payloads that were traditionally borne on crewed aircraft, and instruments not previously used aboard aircraft are being developed and designed for UAS.

The technological improvements in UAS and associated sensors have gained popularity in many disciplines including surveying and mapping for a wide range of environmental applications (Hugenholtz et al. 2012; Bakuła et al., 2016; Jozkow et al., 2016; Sankey et al., 2017, 2018). However, the requirements for each use case differs depending on the complexity of the UAS system and its payload. For example, relatively simple operations such as taking a few airborne photos may involve operations with a small, technologically mature aircraft and an inexpensive payload, which may require a single pilot, no additional ground personnel or activities and little pre-planning. In contrast, more complex operations with larger, technologically less mature aircraft and costly payloads may require multiple pilots, visual observers and ground personnel, logistical planning, training, and the establishment of robust safety procedures.
Our study falls in the second aforementioned scenario of complex operations, where we examine the use of UAS to deploy a light detection and ranging (LiDAR) system to map vegetation and topography in the Arctic tundra of Alaska. The complexity of the UAS and LiDAR payload, in addition to the remoteness and extreme conditions of the study site, made these surveying campaigns very challenging. Given the lack of literature or other resources for best practices and experiences deploying complex UAS in difficult locations (e.g. Arctic), this manuscript seeks to help close that gap by relaying the knowledge and experiences we gained from our UAS operations.

\section{MAIN BODY}

\subsection{Science in the Arctic}

This use case describes UAS operations in the Arctic tundra of Alaska, USA as part of a US Department of Energy led, multinational-laboratory and university project called the Next Generation Ecosystem Experiments (NGEE) Arctic. As permafrost systems in the arctic warm, the landscape is subject to rapid changes such as vegetation shifts and releases of landscape-stored $\mathrm{CO}^{2}$ and methane into the atmosphere, all of which have potential impacts to natural systems across the globe (Schuur et al. 2008; Grosse et al. 2016). The overall goal of NGEE Arctic is to improve global climate model predictions through the better understanding and representation of the Arctic terrestrial system.

The ability of NGEE Arctic to perform scientific observations, experiments, and model earth systems processes depends upon using high-quality data products. Some such data are collected and available outside of the project such as satellite data products, but many of the science questions behind NGEE Arctic 
require detailed surface data products at targeted locations and higher resolutions than is otherwise available. In addition, high resolution maps of topography and vegetation are needed at multiple time points to understand landform evolution and vegetation dynamics at multiple spatial and temporal scales given the transient and dynamic Arctic tundra system.

In order to obtain data products necessary to meet the project goals, we determined that mapping field locations with a LiDAR instrument aboard an uncrewed aerial vehicle (UAV) was the most effective solution. Although we considered using photogrammetric techniques to create the maps, LiDAR was selected to eliminate dependence on good ambient lighting conditions (which can be difficult to obtain at our locations), reduce the need for extensive ground control, and increase the potential data resolution at fine scales and through dense vegetation.

We tasked our field observation team with incorporating UAS into the regular schedule of seasonal fieldwork and identified a subset of the team to focus on details specific to UAS work. This UAS team underwent UAV and payload training, and assembled the documentation, protocols and approvals necessary for safe and efficient UAS work. Since the NGEE Arctic project began prior to including UAS operations, a rigorous fieldwork program was already in place. However, although additional complexities were expected during UAS work, many were difficult to anticipate, and we found no direct resource to guide our use of UAS in arctic tundra.

\subsection{Field UAS Campaign}

2.2.1 Field Location. In this paper, we examine two field campaigns over consecutive summers in 2017 and 2018 to map portions of a $\sim 2.2 \mathrm{~km}$ watershed on the Seward Peninsula of Alaska, USA. The field location is along the Teller road, outside of Nome, AK at latitude $64^{\circ} 44^{\prime} 7.45^{\prime \prime} \mathrm{N}$ and longitude $165^{\circ} 57^{\prime} 35.38^{\prime \prime W}$ (Fig 1). The field site consists of undulating tussock-tundra and shrubland vegetation with a S/SE aspect and 210 m elevation gradient.

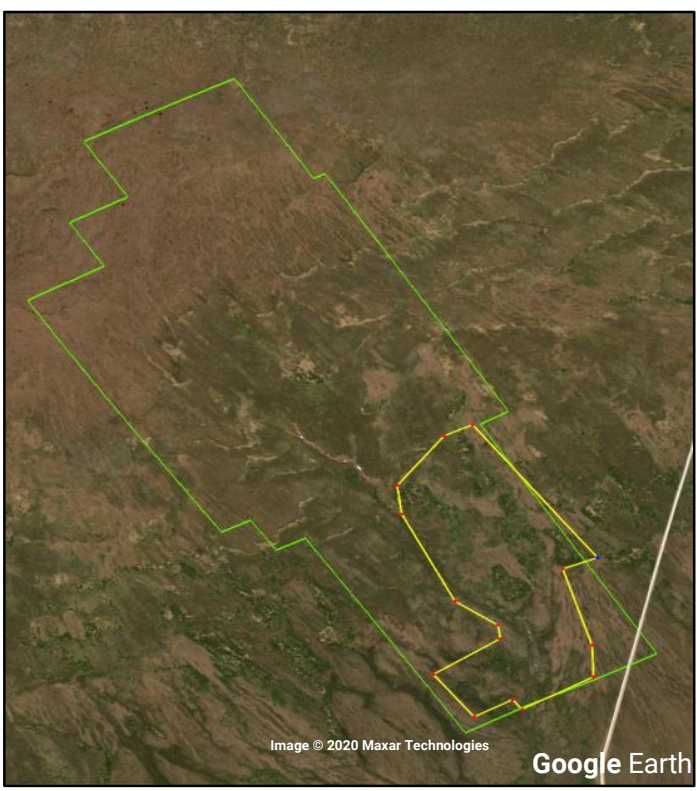

Figure 1. Teller watershed mapping extent in 2017 (green) and 2018 (yellow). Image footprint is approximately $3 \mathrm{~km}$ by $2 \mathrm{~km}$. Teller road shown in white. Map data: Google, Maxar Technologies.
2.2.2 Extent. In 2017, the entirety of the watershed was mapped at a UAV forward speed of approximately $6 \mathrm{~m} / \mathrm{second}$ at an altitude of $35 \mathrm{~m}$ above ground level (AGL), with the LiDAR instrument in single-return mode to obtain point cloud data with a density of 300-500 points per meter square. In 2018, we returned to the site and mapped only about $20 \%$ of the watershed, focusing on the densest areas of aboveground vegetation, and collected dual-return LiDAR data with point densities in the range of 5,000 points per meter square. In the 2018 campaign, we flew the UAV lower and slower, at $2 \mathrm{~m} /$ second forward speed and $20 \mathrm{~m}$ AGL.

2.2.3 Team. The UAS field time was comprised of four personnel in 2017 and five in 2018. The team included the same two UAS pilots and the same operations coordinator for both 2017 and 2018. The roles of payload operator and ground control surveyor were conducted by a single person in 2017, and split between two personnel in 2018 .

2.2.4 Equipment. In 2017, we used a Vulcan Raven UAV (Vulcan UAV Ltd., Mitcheldean, Gloucestershire, UK) with a coaxial quadcopter design (Fig 2; Table 1). In 2018, we operated a DJI Matrice 600 Pro (Table 1; M600, Shenzhen DJI Sciences and Technologies Ltd., Shenzhen, Guangdong, China), which is a hexacopter platform. Both aircraft were powered with lithiumpolymer batteries and electric motors, and controlled with DJI A3-based autopilot flight controllers. For all flight operations, waypoint missions were created and flown using UgCS software (SPH Engineering, Riga, Latvia) and flown in a boustrophedonic ("lawnmower") pattern with at least $50 \%$ side overlap.

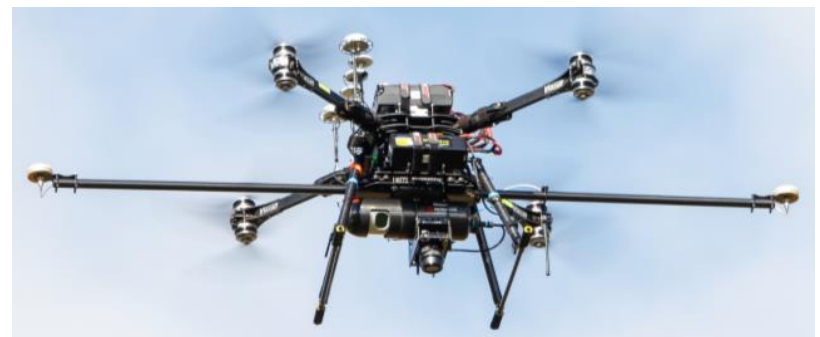

Figure 2. Vulcan Raven aircraft carrying Routescene UAV LiDAR System LidarPod and GNSS antennas, and Sony $\alpha 6000$ payloads.

For both campaigns, we employed a Routescene UAV LiDAR System (Routescene, Edinburgh, Scotland, UK), which is comprised of an RTK GNSS telemetering ground unit, and a rotating 32-laser Velodyne scanner and RTK GNSS/INS air unit (Fig 2).

Ancillary equipment included portable generators, battery chargers, full duplex radio communication headsets, two-way radios, waterproof and shock-resistant rugged hard cases, differential GPS survey system, ground control targets, safety equipment, and multiple laptop computers and mobile devices. To provide a forgiving and even surface on which to conduct takeoffs and landings with the UAV, we built a $2.4 \mathrm{~m}$ by $2.4 \mathrm{~m}$ square landing pad. The landing pad was constructed with an underlying wooden dimensional lumber frame and top made of rigid foam board (R-TECH Insulation Panels, Insulfoam, Puyallup, WA, USA). 


\begin{tabular}{|l|c|c|c|}
\cline { 2 - 4 } \multicolumn{1}{c|}{} & $\begin{array}{c}2017 \text { Vulcan } \\
\text { Raven }\end{array}$ & $\begin{array}{c}2018 \text { DJI } \\
\text { M600 }\end{array}$ & $\begin{array}{c}2019 \\
\text { Gryphon }\end{array}$ \\
\hline $\begin{array}{l}\text { Time per flight } \\
\text { (minutes) }\end{array}$ & 14 & 19 & 23 \\
\hline $\begin{array}{l}\text { Maximum } \\
\text { payload (kg) }\end{array}$ & 3.9 & 5.5 & 12.3 \\
\hline $\begin{array}{l}\text { Turnaround } \\
\text { Time (minutes) }\end{array}$ & 20 & 13 & 10 \\
\hline $\begin{array}{l}\text { System } \\
\left.\text { Volume (m }{ }^{3}\right)\end{array}$ & 0.32 & 0.51 & 0.62 \\
\hline
\end{tabular}

Table 1. Aircraft specifications for 2018 and 2018 field campaigns in Alaska. Details of an aircraft procured in 2019 shown for comparison. System volume includes rugged hard cases for airframe and batteries.

\subsection{Campaign Challenges}

2.3.1 Terrain at the field site is comprised of large hillslopes with undulating topography mostly covered by graminoid tundra, including tussocks formed by tussock cottongrass (Eriophorum vaginatum L.), dwarf shrubs, mosses and lichens (Miller et al. 1984). Generally, tussock tundra may reach heights over $50 \mathrm{~cm}$. Intertussock spaces may be inundated with standing or flowing water during the summer, and small $(<1 \mathrm{~m})$ patches of exposed bedrock are occasionally present. In areas suitable for growth of large shrubs, patches of densely distributed alder and willow over $2 \mathrm{~m}$ in height exist. Areas of bare soil were rarely encountered.

Overland travel by foot was challenging due to uneven distribution and steep slope angles of tussocks, and required sturdy waterproof footwear to prevent cold exposure and injury. Additionally, walking on vegetation could be slippery, the amount of vegetation compression underfoot varied, and views of foot placement were often obscured due to presence of vegetation over ankle height. Locations of standing water were difficult to predict and each footstep required attention and focus to reduce injury potential, though no major injuries were sustained

Transport of personnel and equipment was only possible by foot, as motorized travel could impact the sensitive ecosystem at the center of our research. We hauled equipment by hand, carrying backpacks, pulling sleds across tundra, (designed for use in snow, though no snow was encountered), and wheeling a twoperson game cart (GameTote, Fort Collins, CO, USA). We were able to drive near the site at the southernmost boundary on an improved road and accessed locations within the watershed by either hiking up an unimproved road near the eastern boundary that extended to the north of the site, hiking directly across tundra, or some combination of hiking unimproved road and tundra.

2.3.2 2017 Weather was variable during the 12-day August campaign, with daytime temperatures between $3^{\circ} \mathrm{C}$ and $7^{\circ} \mathrm{C}$ for all but one day, which reached over $17^{\circ} \mathrm{C}$. Rain was common with about half of flight days including rain showers during some point in a given day. Similarly, a little over half of the field days were windy, with wind speeds between $5 \mathrm{~m} / \mathrm{s}$ and $11 \mathrm{~m} / \mathrm{s}$. Low temperatures contributed to slow foot travel, lower carrying capacity by personnel due to the need to carry and wear additional cold-weather gear, and reduced fine motor dexterity and thus slower equipment setup, operation and takedown. Turnaround time between flights (Table 1) was likely lowered, though it is difficult to determine how much was due to cold weather. Low temperatures did not significantly impact equipment, as electronics including batteries, screens, motors, etc. performed within their operational limits. Wind speeds did approach our maximum UAS takeoff and landing wind tolerance of $12 \mathrm{~m} / \mathrm{s}$, but conditions were generally favorable for flight. Rain did reduce our operational efficiency, as infrequent showers would cause a pause in operations and protection of equipment, initially with tarps, and later with a six-person camp tent. Transport of equipment was not affected by water, as equipment was stored in waterproof protective hard cases or tarped.

2.3.3 2017 Equipment reliability proved a source of delays and lost data for numerous reasons. Foremost, the Vulcan Raven airframe experienced such pre-campaign vibration during training and testing at our home elevation of $2100 \mathrm{~m}$ in Los Alamos, NM, that propeller bolts broke, propellers were ejected and motor mount bolts were fractured. After significant troubleshooting and testing, we changed from tri-blade folding carbon propellers to fixed dual-blade propellers and instituted a rigorous airframe check and bolt check procedure between flights. Since the airframe was configured for operations near sea level, we expected reduced vibration and resonance issues in Alaska. Although the Vulcan Raven did perform better in Alaska with more thrust and yaw authority, during one flight approximately $600 \mathrm{~m}$ away from the pilot, the airframe turned around and flew backward toward the set home point and was unresponsive to pilot input. About $100 \mathrm{~m}$ laterally before reaching the home point, the UAV descended faster than a normal landing approach, at an estimated $5 \mathrm{~m} / \mathrm{s}$ and crash landed on soft tussock vegetation. Upon examination, we determined that vibration resulted in detachment of a MT60 bullet connector between a rear motor and electronic speed controller and the aircraft lost the use of that motor during flight. Given the lift redundancy of the other seven rotors, the aircraft maintained airborne status until landing. We also discovered breakage of a motor plate standoff bolt, though it is difficult to determine whether the bolt broke during flight or as a result of the hard landing. The airframe and payload was largely undamaged and after 1.5 days, we were able to make sufficient repairs and test for airworthiness to return the entire system to service and complete the campaign.

Additional transient equipment malfunctions occasionally further delayed operations. At times, both the $\mathrm{UgCS}$ waypoint software and DJI Go software suffered periods of unresponsiveness. On two occasions, the onboard-aircraft DJI A3 flight controller settings reverted to factory settings and it was necessary to reconfigure the flight controller prior to additional operations. Wireless connection (over $2.4 \mathrm{GHz}$ wifi) between mobile device or laptop to handheld DJI Lightbridge 2 controllers and Routescene Ground Station intermittently failed to connect and toggling airplane mode, or resetting devices was sometimes necessary. The Routescene UAV LiDAR System required infrequent system restarts due to inertial navigation system (INS) errors and once required repositioning of the infrared camera trigger used to capture photogrammetry during LiDAR data collection.

2.3.4 2018 Weather. The $\sim$ two day field campaign in July 2018 saw more favorable weather with days near $15^{\circ} \mathrm{C}$, no rain and light $\sim 3 \mathrm{~m} / \mathrm{s}$ wind, though the rest of the campaign at other nearby field locations (not covered in this paper) included constant heavy rain for two of 13 days. 
2.3.5 2018 Equipment Reliability. The M600 UAS platform was generally reliable, although twice the DJI software displayed electronic speed controller errors and system restarts were necessary to eliminate the errors. We had the use of four complete sets of batteries and more than once, flight operations were slightly delayed to await battery charging, but could have been alleviated with five complete battery sets. Similar software unresponsiveness, glitches, and freezes occurred with $\mathrm{UgCS}$ and DJI platforms as in 2017, as did occasional wifi connection issues. The Routescene UAV LiDAR System required a system reboot once or twice, but connectivity between air unit and ground unit, and between mobile device and ground unit was satisfactory and QA/QC criteria during data collection was met without incident.

\subsection{Metadata and Analytical Techniques}

2.4.1 Metadata Content and Analysis. This paper presents metadata associated with each of our field campaigns. The entirety of the 15-day 2017 field campaign was spent LiDAR mapping the Teller site, while two of 13 days in 2018 in the field were spent collecting LiDAR data at the same field site. For the purposes of this analysis, we chose not to include the remaining 11 days in 2018 mapping other sites due to different daily travel times, local weather patterns, access points, and terrains.

To determine the time spent in person hours for different activities, the number of hours for each activity category (for example, "active flight operations") was summed for all personnel. The percentage contribution of that activity was then calculated by dividing the category sum by the total number of hours spent on the campaign. For example, in 2017 the team spent a total of 68 person hours on active flight operations, and the total campaign took 967 person hours, so $68 / 967=7 \%$ of the campaign effort that was spent actively flying the UAS

In 2017, the raw number of hours spent on each activity category was used to calculate the percentage of the total campaign effort. In 2018, the raw number of hours was used with two exceptions to prevent undue influence of time spent on the entirety of the campaign not specific to the two days at the Teller site: 1) the preparation and travel time was scaled by multiplying the number of hours spent in each category by $2 / 13$ to represent the two days spent in the field, divided by the number of total field days; and 2) despite good weather at the Teller site in 2018, weather delays were included by multiplying the number of hours of total delays by $2 / 13$ since we had the opportunity to choose good-weather days at Teller and to account for the random factor of weather in a multi-week field campaign. The total number of hours lost due to a completely rained-out field day was calculated by multiplying the number of personnel by the average field day length in 2017 (13.15 hours/day). Over both years, time spent in a given category was only counted if it pertained directly to the campaign of interest, e.g., obtaining UAS pilot licenses, which is a preparation activity that applies to all campaigns and not specifically to these campaigns, was not included.

Data sources presented herein came from multiple sources. The primary systematic sources were flight logs, preflight checklists, and battery logs and were used to determine the timing of each component of operations and corresponding levels of effort. Flight logs contained information including timing and location of each flight, environmental conditions, personnel, and flight and data characteristics. To ensure safe charging and to track battery use and performance, we recorded metrics on battery discharging and charging such as voltage at discharge and charge and the quantity of charge (ampere hours) for each charge cycle. In 2017, one team member kept a detailed field notebook that recorded general team efforts, notes on flight successes or failures, in-field arrival and departure times, temperature and weather, and other activity-related notes. Data from 2017 relied heavily on this field notebook data source. Additionally, other sources were sometimes necessary to constrain activity efforts and included emails, calendars, mobile device communications between team members and safety points-of-contact, FAA filings (notice to airmen, NOTAM) and LiDAR data files.

\subsection{Results}

2.5.1 Campaign Totals. In 2017, the UAS team mapped the entirety of the nearly 220 ha watershed, whereas the focus of the 2018 campaign was on less than a 50 ha targeted area (Table 2). Despite this, additional raw data was collected in 2018 as a result of flying lower, slower, and enabling the higher data collection rate of dual-return LiDAR. We averaged less than three flights per day in 2017, but more than doubled that in 2018. Changes and additions to the amount of equipment (including protective hard cases), resulted in a slight $9 \%$ increase in total equipment volume.

\begin{tabular}{|l|c|c|}
\hline & 2017 & 2018 \\
\hline Hectares Surveyed & 216.52 & 45.65 \\
\hline Gigabytes of Data & 45.5 & 50.2 \\
\hline \# Flights & 34 & 12 \\
\hline Flight Hours & 6.52 & 3.84 \\
\hline Flight parameters & $6 \mathrm{~m} / \mathrm{s}, 35 \mathrm{AGL}$ & $2 \mathrm{~m} / \mathrm{s}, 20 \mathrm{AGL}$ \\
\hline \# Campaign Days & 12 & 1.7 \\
\hline \# Flights / Day & 2.8 & 7.1 \\
\hline Total Person Hours & 967 & 158 \\
\hline \# Personnel & 4 & 5 \\
\hline Equipment volume & $1.8 \mathrm{~m}^{3}$ & $1.96 \mathrm{~m}^{3}$ \\
\hline
\end{tabular}

Table 2. Campaign sums for 2017 and 2018. Note: equipment volume includes all UAS-related equipment but excludes personal gear.

2.5.2 Levels of Effort. As a percentage of the campaign in 2017 , the largest effort was spent in preparatory activities, with a $\sim 10 \%$ decrease in 2018 (Fig 3). The category of "Preparation" included gaining airframe flight currency immediately prior to departure, inventorying, packing and shipping equipment, and planning field logistics. Note that despite the great amount of time spent troubleshooting and testing the Vulcan Raven airframe before the 2017 campaign, these hours were not included in this analysis.

Travel to and from AK across both years was similar, and the relative amount of time spent driving between Nome and the field location increased in 2018, as shorter days were spent in the field. Hiking by foot to and from different staging areas within the watershed comprised $5 \%$ of the campaign in 2017 , while hiking was unnecessary in 2018 due to close proximity to the staging area from the road. Ground control efforts including placement of ground control targets and DGPS survey of those targets took 5\% of the campaign effort in 2017, and was reduced to half that in 2018 since some ground control targets were reused from the previous year. 


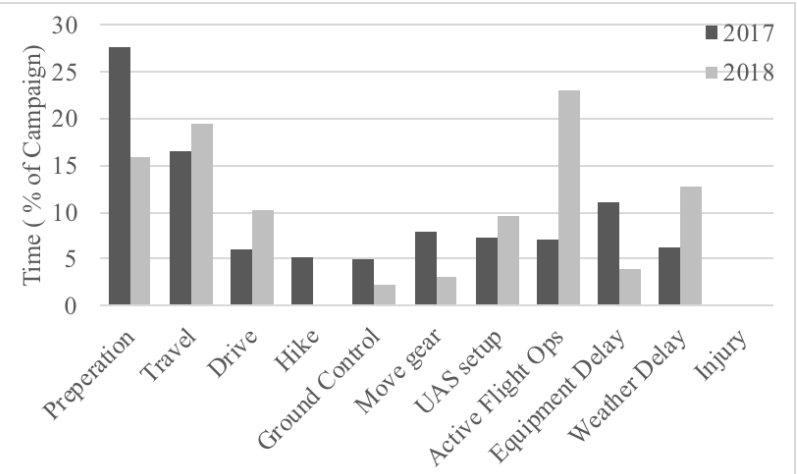

Figure 3. Time spent in each category as a percentage of the total campaign time.

The activities surrounding establishing UAS equipment on the ground and conducting flight operations varied by year. The team spent just $3.2 \%$ of campaign time physically moving gear by hand, sled or backpack in 2018 between the single staging area and nearby vehicles compared with $7.9 \%$ in 2017 among five staging areas across the watershed. UAS setup and takedown time was similar between years but active flight operations comprised only $7 \%$ of total campaign time in 2017 vs. nearly $23 \%$ in 2018.

Equipment delays were substantial in 2017, and at over $11 \%$ of campaign time, were the single largest allocation of on-the ground effort. Delays due to equipment issues remained in 2018 but were reduced to $4 \%$. Weather (primarily rain) also impacted operations across both years and accounted for $6-13 \%$ of total time. No injuries to personnel were incurred either year.

Comparing year-to-year efficiencies, it took more effort in 2017 to fly the UAS for a given time period, and thus a given spatial area than in 2018 (Table 3). However, flying lower and slower in 2018 resulted in fewer hectares covered per flight hour.

\begin{tabular}{|c|c|c|c|c|c|c|}
\hline & \multicolumn{2}{|c|}{$\begin{array}{l}\text { Person hours } \\
\text { per flight } \\
\text { hour }\end{array}$} & \multicolumn{2}{|c|}{$\begin{array}{l}\text { Person hours } \\
\text { per hectare } \\
\text { surveyed }\end{array}$} & \multicolumn{2}{|c|}{$\begin{array}{l}\text { Hectares } \\
\text { surveyed per } \\
\text { flight hour }\end{array}$} \\
\hline & 2017 & 2018 & 2017 & 2018 & 2017 & 2018 \\
\hline $\begin{array}{l}\text { Including } \\
\text { Weather and } \\
\text { Equipment } \\
\text { Delays }\end{array}$ & 14.3 & 4.4 & 4.5 & 3.4 & 0.9 & 0.7 \\
\hline $\begin{array}{l}\text { Excluding } \\
\text { Weather and } \\
\text { Equipment } \\
\text { Delays }\end{array}$ & 11.9 & 3.6 & 3.7 & 2.9 & 3.2 & 1.3 \\
\hline
\end{tabular}

Table 3. Levels of effort required to conduct one flight hour, map one hectare of land, and area surveyed per hour.

2.5.3 Data Quality was high both years with LiDAR returns from vegetation subcanopy features and ground. Obtaining a greater number of ground returns through areas of dense vegetation was a primary goal of 2018 , and that goal was achieved (Fig 4).

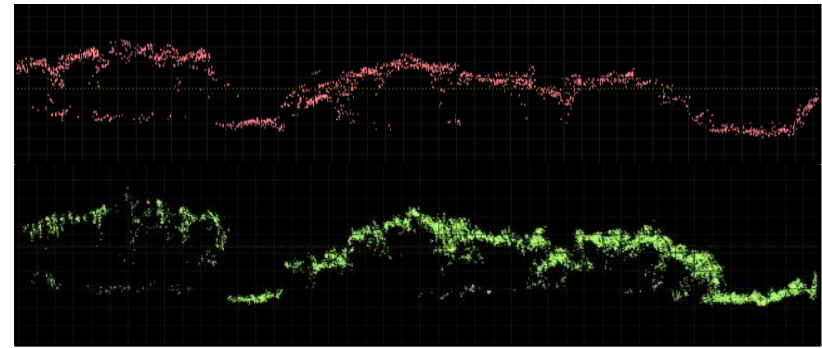

Figure 4. Profile views of LiDAR data over the same densely vegetated area in 2017 (top) and 2018 (bottom).

When comparing a digital terrain model (DTM) of a targeted area of tall shrubs between years, 2018 showed a large number of lower points, which may be ground or subcanopy vegetation returns compared to 2017 (Fig 5). Confidence was gained in this interpretation, as adjacent areas devoid of taller vegetation features registered identical (zero difference) values between years.

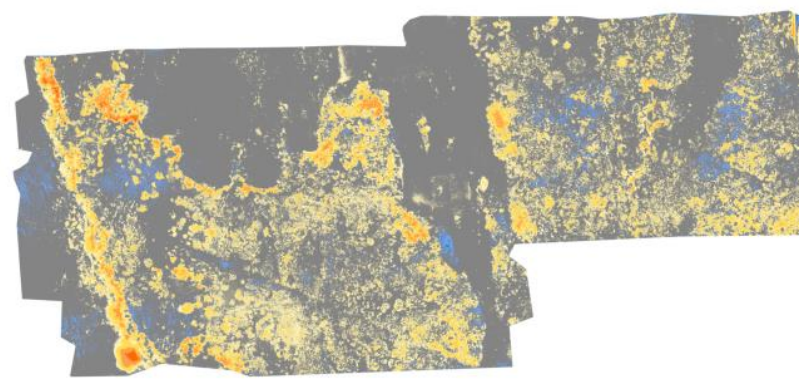

Figure 5. DTM of 2017 subtracted from 2018 of a targeted area. Yellows, oranges and reds indicate negative values (lower points in 2018), grey represents zero difference and blue represents positive values.

\section{CONCLUSIONS}

\subsection{Best Practices Framework}

We developed a UAS operational best practices framework for our work in the Arctic tundra through our preparatory activities, and by analyzing these data over the course of the two field campaigns. We arrived at a best practices framework by examining the challenges we faced and identifying opportunities for our team to respond differently and improve the success of the project.

We specifically examined the challenges presented by weather, equipment-related issues, terrain complexity, and vegetation density. We investigated the causes of impacts to our operations due to low temperatures, rain, and high winds. To identify opportunities to respond to equipment delays and failures, we looked to pinpoint system interdependencies and single points of failure. Terrain complexity increased foot travel time across the tussock tundra and led to additional safety risk, and we sought to minimize these impacts. The growth and distribution patterns of shrub patches at our field location made it difficult to obtain LiDAR returns beneath vegetation, and we examined our data to find areas where coverage was poor or error rates were high.

The best practices framework we developed are underlined by three basic principles that we apply to all challenges to maximize overall success: 1) increase system resilience; 2) increase operational efficiency; 3) increase safety. These three precepts are often interrelated and their application often begets additional 
benefits in multiple areas including team communication, inclusivity and performance satisfaction. In many cases, we arrived at meeting these principles by thinking about how we could either avoid or tolerate each individual challenge. Although our focus is in succeeding specifically in the Arctic tundra system in which we work, these practices can be generalized to other operations and for other systems. In the following, we examine each challenge and the steps we took to maximize resilience, efficiency and safety across our equipment and team, and achieve operational success

\subsection{Challenge: Weather}

3.2.1 Precipitation. The main impacts of weather on our operations involved direct impacts (realized or potential) to our equipment and personnel (though indirect effects were incurred at times when driving was slowed due to heavy rain and corresponding road conditions). Since we worked with many electronic components like laptops, chargers, and the UAV itself, we identified avoidance as the best method to increase our three underlying principles of resilience, efficiency and safety. At first, we felt that utilizing tarpaulins and waterproof equipment cases would be adequate, and although resilience and safety criteria were largely met, the systems were not efficient. We later employed the use of a camping tent large enough to house our completely setup UAV (which takes time to dismantle and store in waterproof containers) and a 5-person team. The use of the tent met the two criteria and also greatly increased efficiency in taking shelter between intermittent rainstorms. Additionally, when possible, we used water-proof or -resistant equipment and clothing to tolerate some exposure to rain without expending effort in actively providing in-field protection.

3.2.2 Temperature. Low temperatures were not low enough to significantly impact our equipment functionality, but did affect personnel. Cold weather reduced hand and foot dexterity and could lower efficiency and expose the team to additional risk. We avoided cold weather by actively heating ourselves, using hand and foot warmers. Similar techniques could be used to heat equipment and batteries if necessary using items like hot water packs or electric heaters. Tolerating the cold by maintaining warmth was also identified as a necessary step through the use of insulated clothing for personnel or insulated containers for equipment. Utilizing a thermal mass such as water-filled containers could also be used to buffer impacts to equipment

3.2.3 Wind primarily made UAV takeoffs and landings more challenging to conduct safely and efficiently, but also made verbal communication difficult. Avoiding wind during takeoffs and landings was sometimes achieved by careful positioning of the landing area if nearby land or vegetation features were available to offer wind protection, but often the wind was steady and we thus placed the landing pad in open areas to reduce turbulence from close objects. Using a large enough landing pad size was also important in providing flexibility for the pilot to land the UAV windy conditions. The landing pad was approximately four times the size necessary to land the size of our particular UAVs by our qualified pilots in ideal conditions. To improve safety for all team members during landing, especially during windy conditions, the pilot was positioned downwind of the landing area with the front of the aircraft facing away from the pilot such that the pilot could apply even pitch command while the UAV descended. Furthermore, any gusts that pushed the aircraft toward the pilot would ideally elicit a natural "push away" thumb response by the pilot to pitch the aircraft forward and away from the pilot. However, this practice can be challenged by the event of the aircraft being unresponsive and drifting towards the pilot. Team members were positioned behind the pilot to eliminate the need for the pilot to maintain spatial awareness of other personnel. Verbal communication was improved by adopting clear and concise communication styles similar to that used in aviation. We also used wireless headsets for easy hands-free communication when in close proximity to one another $(\sim 100 \mathrm{~m})$ and handheld two-way radios for communication at farther distances (up to $2 \mathrm{~km}$ ).

With multiple weather-related challenges, efficiencies could be reduced to zero despite all efforts if the weather was poor enough. Thus, planning the field campaigns for suitable weather, when possible, was helpful. More importantly, ensuring that the field team was prepared and rested enough to take advantage of periodic windows of good weather was critical. In the summer at high latitudes, with day lengths approaching 24 hours, we were able to occasionally work $\sim 18$ hour days to maximize data collection specially during good weather windows in this extreme environment.

\subsection{Challenge: Equipment}

3.3.1 Single points of failure, or system components which, if failed, would cease operations of the whole system, were examined in our equipment, and also as those failure points pertain to personnel, in their specialized roles or knowledge of equipment. Single points of equipment failure were critical particularly by the remoteness of the campaign where no specialized stores are available and shipping equipment in can take several days to weeks. Therefore, hardware component points of failure were identified and where possible, avoided. For example, both UAVs employed redundant motor systems such that a safe landing would be possible in the event of motor failure. Other critical equipment components were duplicated if budget allowed, such as battery chargers, mobile devices and tools. Avoiding single-point failures was also achieved by ensuring that multiple personnel were trained or had familiarity with critical components of the equipment, such that operations were possible if a single personnel was unavailable for some reason.

Often, failure points could not be avoided, such as with expensive items, or with those impractical to duplicate. In many cases, when we invested in quality equipment that was selected for durability and longevity, this minimized reductions in operational problems. We discovered that not all of the many hardware constituents of a UAS and associated operations are held to the same manufacturing standard and level of reliability, and that using cheaply or poorly made products often introduced great decreases in efficiency and thus increased mission costs.

3.3.2 Maintenance and testing of our equipment was critical to ensure safe and successful operations. We developed a rigorous system of checks and balances that we applied to the planning stages through campaign completion. Broadly, we enacted multiple checklists including packing lists, to-do lists, beginning-of-day checklists, pre-flight checks, post-flight checks, data quality checks, and multiple procedural documents and checklists specific to sub-systems and components. We designated certain parts of some checklists as necessary for double-checking by more than one individual, especially those related to flight-critical UAV components. On the daily or subdaily timescale, any maintenance issue encountered was immediately corrected or noted, discussed, and decisions were made to continue or suspend operations pending correction of the issue. Over longer periods of time, flight hours and battery 
charge cycles were carefully tracked, and predetermined maintenance schedules for various components were adhered to.

Testing the multiple electronics systems was also important because functionality of so many different pieces of the entire system was necessary, often simultaneously, to complete a given flight. We identified interdependencies of various systems, for example a wireless router through which numerous devices communicated and tested those systems in different physical and software configurations. Testing the systems often revealed single points of failure or recurrent points of weakness and gave us the opportunity to increase resilience or efficiency with redundant or reconfigured equipment. Testing in assorted arrangements also provided a springboard for developing contingency plans when failures or difficulties were encountered. In order to test systems such as satellite reception of the UAV at high latitudes, along with mission planning software functionality and accuracy of the base digital elevation maps it relied upon, we often deployed an inexpensive small DJI Phantom 4 Advanced UAV, which had similar or identical software to the large and costly primary UAV and payload before it was deployed.

Often in concert with testing various systems prior to campaigns, maintaining personnel training was helpful in keeping the team prepared for safe and efficient operation of all equipment and software. Though pilot flight currency with the UAV in question was the top priority in maintaining training, currency of the payload operator with the payload system, the surveyor with the survey equipment, the operations coordinator with the planning software and team UAS currency in general allowed for smooth operations. Since our team did not conduct UAS projects yearround, it was especially important to refresh our knowledge and skills before each campaign.

A surprisingly large part of maintaining a properly functioning UAS was related to keeping various batteries charged for use during daily operations. In addition to the UAV batteries, rechargeable batteries were present in or needed for items such as laptops, tablets, headsets, two-way radios, UAV controllers, UAV ground station, DGPS rover, DGPS controller and DGPS ground station, UAV LiDAR system ground station, handheld GPS, and small UAV batteries and controller. In all, 25 small $(<100$ watt hour) lithium batteries that were not integrated into equipment were utilized. All batteries were required on a daily basis and we employed scheduled charging at night among all team members.

3.3.3 Team communication was integral to our ability to operate equipment safely and effectively. We encouraged a communication style of clear and concise verbal and nonverbal communications, where background noise and misinterpreted messages could have serious consequences. We instituted a procedure of engaging in predefined conversations during operations in a sequential manner, identifying both the content of the interactions and parties involved. For example, immediately prior to takeoff, the operations coordinator would request verbal responses from multiple parties, starting with the pilot then the payload operator to confirm readiness of the UAV and LiDAR systems, after which the pilot would ask the backup pilot if all was clear for takeoff and upon confirmation, the pilot would notify the entire team of impending propeller spin up and takeoff.

We also fostered both a culture of accepting personal responsibility for actions, while recognizing that any one member of the team is fallible and that many parts of our procedures require a second or third person to verify that actions were performed correctly. Frequently throughout an operations day, we would create opportunities for the entire team to pause their activities to focus on discussing questions and concerns about previous or upcoming work. We monitored the levels of physical and mental fatigue by checking in with one another, and each team member was empowered with the ability to pause or stop the activities of the team for any reason.

\subsection{Challenge: Terrain}

The tussock-tundra terrain was challenging primarily because foot travel was physically demanding and slow. Since we weren't able to modify the terrain, we raised resilience, efficiency and safety by evaluating multiple methods of travel such as by foot, automobile, helicopter or all-terrain vehicle. Despite exploring motorized options, we deemed foot travel to be the best option and considered other ways to haul equipment. We were hopeful that a game cart, designed for hauling big game out of complex terrain would be effective, but instead, dragging sleds across the low vegetation proved to be the best choice, as each team member could work at their own pace, and transport via sled was most efficient.

We aimed to maximize the safety of our team in a few ways. First, team members were asked to evaluate their own physical fitness with respect to hiking many kilometers in such terrain. We then identified and used appropriate personal equipment, namely sturdy waterproof footwear, to protect against ankle sprains and wet feet. All team members were required to undertake safety-related training such as bear safety and first aid training, and to develop and follow emergency procedures. As an additional safety measure, the team carried satellite phones in the event of emergency.

\subsection{Challenge: Vegetation Density}

The presence of dense vegetation presented unique challenges at our field locations. Poor resolution of the ground surface beneath shrubs resulted in difficulty preparing accurate DTMs to meet project goals. To combat this problem, we flew lower to the ground and with slower forward speed to increase the number of returns per square meter. We also learned to fly the LiDAR instrument at oblique angles to the ground to improve the chances of penetrating vegetation.

We observed high error and reduced accuracy in multiple areas of our data collection footprint and identified multiple paths to making improvements. First, we constrained the process of INS initialization of the LiDAR instrument by flying the UAV in smooth movements similar to fixed wing aircraft flight, with gentle throttle inputs, and with small variations about all axes of pitch, roll and yaw. Second, we considered the satellite configuration that would be present at the time of flights to ensure that the UAV LiDAR system would have adequate coverage to obtain accurate RTK solutions. Lastly, we deployed additional LiDAR-reflective ground control and maximized the survey accuracy of those points to improve ground validation.

\subsection{Summary}

Our operational success in UAS LiDAR work in the arctic tundra relied greatly on the efforts of the entire field team and LiDAR vendor to develop a set of best practices specific to our needs. We built our UAS program around three fundamental concepts: resilience, efficiency, and safety. Improvements in system and team resilience was achieved through incorporating adaptability 
with redundant and high-quality equipment, and well-trained communicative personnel. Efficiencies were realized by maximizing our return on effort and examining all aspects of operation. Safety was integrated into the underlying operational framework of the project and facilitated every other component of our work.

We accomplished our UAS project goals by collecting metadata from field logs, communications, and documentation, and leveraged that data to make improvements. Analyzing this metadata revealed inefficiencies and showed us where we spent the greatest amount of effort and funds. Based on these analyses, we were able to modify our strategies and achieve better results on subsequent campaigns. Although we did not seek to include metadata collection and analysis from the outset of our UAS program development, we now recognize the immense value of such tools to augment our research goals and recommend these approaches for future projects.

\section{ACKNOWLEDGEMENTS}

Funding was provided by the Next-Generation Ecosystem Experiments (NGEE Arctic) project, supported by the Office of Biological and Environmental Research in the U.S. DOE Office of Science.

\section{REFERENCES}

Bakuła, K., Ostrowski, W., Szender, M., Plutecki, W., Salach, A., \& Górski, K. (2016). Possibilities for using lidar and photogrammetric data obtained with an unmanned aerial vehicle for levee monitoring. International Archives of the Photogrammetry, Remote Sensing \& Spatial Information Sciences, 41.

Conte, G., Kleiner, A., Rudol, P., Korwel, K., Wzorek, M., \& Doherty, P. (2013). Performance evaluation of a light-weight multi-echo lidar for unmanned rotorcraft applications. International Archives of the Photogrammetry, Remote Sensing \& Spatial Information Sciences, 40, 4-6.

Grosse, G., Goetz, S., McGuire, A. D., Romanovsky, V. E., \& Schuur, E. A. (2016). Changing permafrost in a warming world and feedbacks to the Earth system. Environmental Research Letters, 11(4), 040201.

Hugenholtz, C. H., Moorman, B. J., Riddell, K., \& Whitehead, K. (2012). Small unmanned aircraft systems for remote sensing and earth science research. Eos, Transactions American Geophysical Union, 93(25), 236-236.

Jozkow, G., Totha, C., \& Grejner-Brzezinska, D. (2016). UAS TOPOGRAPHIC MAPPING WITH VELODYNE LiDAR SENSOR. ISPRS Annals of Photogrammetry, Remote Sensing \& Spatial Information Sciences, 3(1).

Miller, P. C., Miller, P. M., Blake-Jacobson, M., Chapin, F. S., Everett, K. R., Hilbert, D. W., ... \& Roberts, S. W. (1984). Plant-Soil Processes in Eriophorum Vaginatum Tussock Tundra in Alaska: A Systems Modeling Approach: Ecological Archives M054-002. Ecological Monographs, 54(4), 361-405.

Sankey, T., Donager, J., McVay, J., \& Sankey, J. B. (2017). UAV lidar and hyperspectral fusion for forest monitoring in the southwestern USA. Remote Sensing of Environment, 195, 3043.
Sankey, T. T., McVay, J., Swetnam, T. L., McClaran, M. P., Heilman, P., \& Nichols, M. (2018). UAV hyperspectral and lidar data and their fusion for arid and semi-arid land vegetation monitoring. Remote Sensing in Ecology and Conservation, 4(1), 20-33.

Schuur, E. A., Bockheim, J., Canadell, J. G., Euskirchen, E., Field, C. B., Goryachkin, S. V., ... \& Mazhitova, G. (2008). Vulnerability of permafrost carbon to climate change: Implications for the global carbon cycle. BioScience, 58(8), 701-714. 